\title{
Teaching ESP Terminology- Case Study Agricultural University of Tirana (AUT)
}

\author{
Enkeleda Jata \\ $\mathrm{PhD}$, Agricultural University of Tirana
}

\begin{abstract}
English for Specific Purposes (ESP) focuses on learners' specific needs in a particular profession. There are different reasons why people study a language. ESP is starting to play an important role in today's world. The aim of this article is to find the difficulties encountered by the students when learning the terminology of Agriculture and Environment. For this reason, 103 questionnaires were collected. The questions are based on the process of learning-teaching specialized vocabulary. They provide feedback on student's difficulties in learning ESP terminology. The main aim is to teach students basic and advance working knowledge, so they can communicate in English in the area of their study. The focus of this study is to present a detailed description of the students' needs and difficulties in learning ESP terminology.
\end{abstract}

Keywords: ESP learners, language teaching, teaching methods etc.

\section{Introduction}

The Agricultural University of Tirana (AUT) offers ESP courses to students who study in different study programs. ESP course is a compulsory subject in the first year of their bachelor degree. Since English has become the dominant language used in science and in other fields, students are then required to learn English for employment purposes as well as for academic research. Different scholars and academics are nowadays highlighting the importance of ESP courses. The motivation for this study originates from the need to analyze the process of acquiring new terminology in ESP courses. First of all, it's important to clarify what is the aim of English for specific purposes (ESP). The aim of ESP courses is to enable students to use it for academic or occupation purposes. As stated by Basturkmen.H., ESP has functioned to help language learners cope with the features of language or to develop the competencies need to function in a discipline, profession or workplace (Basturkmen,H., 2006). According to Musikhin, ESP should be considered to 'develop the learners' overall communicative competence in the field of their professional activity, and to lay the foundation for further learning and refinement of language skills" (Musikhin,2016). According to Dudley-Evans \& St. John, 1998, they give the following definition:

\section{Absolute Characteristics}

ESP is designed to meet specific needs of the learner.

ESP makes use of the underlying methodology and activities of the disciplines that it serves

ESP is centered on the language appropriate to these activities in terms of grammar, lexis, register, study skill, discourse and genre

\section{Variable Characteristics}

ESP may be related to or designed for specific disciplines

ESP may use, in specific teaching situations, a different methodology from that of General English

ESP is likely to be designed for adult learner, either at a tertiary level institution or in a professional work situation

ESP is generally designed for intermediate or advanced students. Most ESP courses assume basic knowledge of the language system, but it can be used with beginners (Dudley- Evans \& St. John, 1998) 
ESP courses are designed to meet students' specific needs to deal with real situations at work. The books and materials used in the class are developed by English teachers for these specific classes, and students are exposed to authentic materials. Teachers' duty is to design a syllabus which can serve to students' needs in order to adapt to today's requirements. Students do not need to be experts of their area of study in order to learn ESP, but they need to have some basic knowledge of the field. Meanwhile, a certain level of proficiency is required from the students in order to attend the course successfully. ESP is more a learner-centered approach rather than a teacher-centered approach, where students' needs are the primary goals to be achieved and students can give their contribution to make further changes in the course syllabus. Dudley-Evans and St. John (1998), prefer to use the term "practitioner" rather than teacher. They highlighted that ESP practitioners need to accomplish this work as a/an: 1. Teacher 2. Course designer and materials designer 3.Collaborator 4.Researcher 5.Evaluator. Dudley-Evans has mentioned that ESP teaching goes beyond teaching just language.

\section{Teaching New Terminology}

The mastery of English language terminology is a fundamental and crucial component for ESP students. It is very challenging for the ESP teachers to perform both the task of English teachers and have good knowledge of all the students' subjects. Teaching ESP is like teaching all the courses in that field. Choosing the appropriate methodology to teach ESP courses is another challenge that the teachers face in order to run a successful ESP course. Another crucial issue is that teachers need to be aware of different learning approaches such as kinesthetic, visual, auditory and reading/writing learners in order to use different methodologies and approaches so that all students can benefit. As Hutchison and Water highlighted that the starting point of teaching a language is to understand how people learn (Hutchison \& Water, 1987). The teacher's role in ESP courses is to be the facilitator of the learning process.

As Quero and Coxhead (2018) mentioned planning is essential in deciding what needs to be learnt and how it is best learnt. Learning the technical terms in isolation is difficult for students, thus teachers should develop learners'skill in apply strategies to deal with the vocabulary they encounter (Quero\&Coxhead, 2018). In English, specialized words have a particular meaning within a particular subject. Specialized words can be learned and understood by studying the field. Word knowledge is a key component of language acquisition, and without enough receptive vocabulary, it is not possible to achieve good reading comprehension of academic or specialized texts (Laufer 1989; Nation 2013 Cit. Quero and Coxhead, 2018). Students need to be aware that any error in written or spoken language interferes with the meaning of the message they want to convey.

It is quite normal that students have difficulties in specialized words, but the techniques that teachers will use should facilitate the learning process. Before focusing in which vocabulary to learn it's important to have an idea about the frequency of the word. Schmitt and Schmitt (2012) divided the vocabulary in three categories high-frequency, mid-frequency and low-frequency. In high-frequency vocabulary were included the 3000 words families of English. Low-frequency vocabulary includes words that are rare in all discourses beyond the 9000 frequency level. Mid-frequency words between 3000-9000 frequency levels.As Schmitt and Schmitt(2012) mentioned technical words are low frequency thus, learners who know high and mid-frequency vocabulary have high probability to acquire low-frequency vocabulary.

Nation mentioned when learning a new word it's essential to know its form, its meaning and its use (Nation, 2000). Nation (2000) emphasizes that the activities in a language course can be classified into the four strands - meaning-focused input, language focused learning, meaning-focused output, and fluency development. Meaning-focused output activities where students will prepare talks/conversation about the topic the have read; meaning-focused input activities students will be interested in the input and try to understand it; language-focused learning focuses on language feature such as grammar, discourse, spelling etc; and the last fluency development focuses on developing reading skills including activities such as skimming and scanning, speed reading etc. (Nation,2000). According to Nation (2007) each strand should have an equal amount of time; teachers are responsible to check if there is a good balance of the strand (Nation, 2007).

\subsection{Terminology teaching in ESP courses can be based on the following suggestions:}

ESP teachers are responsible to provide to the students extra materials that suit to their learning goals; to choose appropriate materials according to the needs in the global market. Bringing extra reading materials in the class is necessary for vocabulary learning. First of all, they can study the words in meaningful contexts and become more competent in their 
specific disciplines. When choosing the extra reading materials, take into consideration their current level of comprehension, and then gradually introduce to the students the linguistic feature.

Teach students how to look on specialized dictionaries, or use the internet to search for more information, emphasize that terms have restricted meaning across disciplines. Teach them to consult with an expert of the field, to clarify the exact meaning of the terms and to offer the best translation in Albanian. Teaching high-frequency words, if students know highfrequency words, will increase the possibilities to learn low-frequency words.

Some techniques that can be used in ESP course: visual technique: - some words are difficult to explain, showing them pictures or real objects can help them understand the terms; definitions and explanation:-giving the definition of the words in both languages; matching- matching words with sentences or pictures; giving the synonym or antonym of the words for example- ground- field or landscape; grains- particles (synonym) or integration- separation (antonym); guessing from the context: it means to understand it from the context by activating background knowledge. Teachers should guide students to success of being fluent and confident in all the areas of using ESP. Some suggestions that can be applied in class to help in memorizing and learning new terminology:

organizing discussions related to the field of their study, by dividing the students based on their skills level and giving them freedom to contribute by giving suggestions regarding the topics.

encourage students to work and research independently rather than memorizing language rules

choose materials which suit the students' needs

help students how to fit into target situation by organizing role-plays in class; prepare students to be able to present in front of an audience

make a presentation on aspects of agriculture and environment and it increases the likelihood to introduce and acquire new vocabulary

enlarge their knowledge through reading extensively

\section{Findings}

The data for this research was collected from 103 students at the Faculty of Agriculture and Environment. Responses collected from students are analyzed and serve as recommendations for further inclusions in ESP courses. The questionnaire is divided in three sections. All the questions are based on students' difficulties of acquiring new terminology and teachers' methodologies. Below you can find the analyses of some important questions.

Question- When you read agriculture texts; do you need to translate the new terminology to understand the text?

As you can see in the graph 1 , it shows the need of the students to translate the new terminology of a text, where $34 \%$ always, $43 \%$ very often and $23 \%$ rarely. Sometimes terminology translation alone is not enough to understand the content of the text.

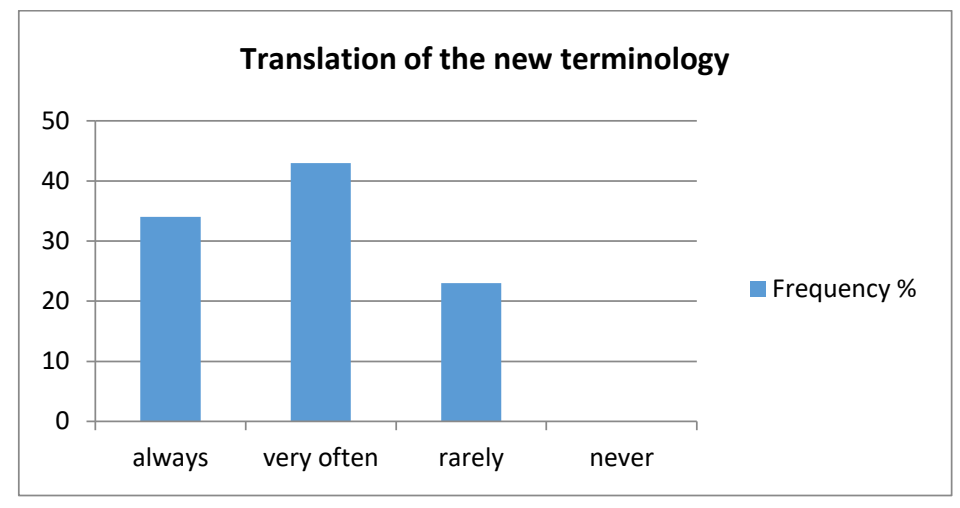

Graph 1.

Question- Do you encounter difficulties in acquiring the new terminology of agriculture? 
The statistics show that $31 \%$ always, $48 \%$ very often and $21 \%$ rarely encounter difficulties in acquiring the new terminology of agriculture (Graph 2). At the same time, having difficulties acquiring the new terminology of agriculture shows lack of sufficient techniques and methods applied in the class.

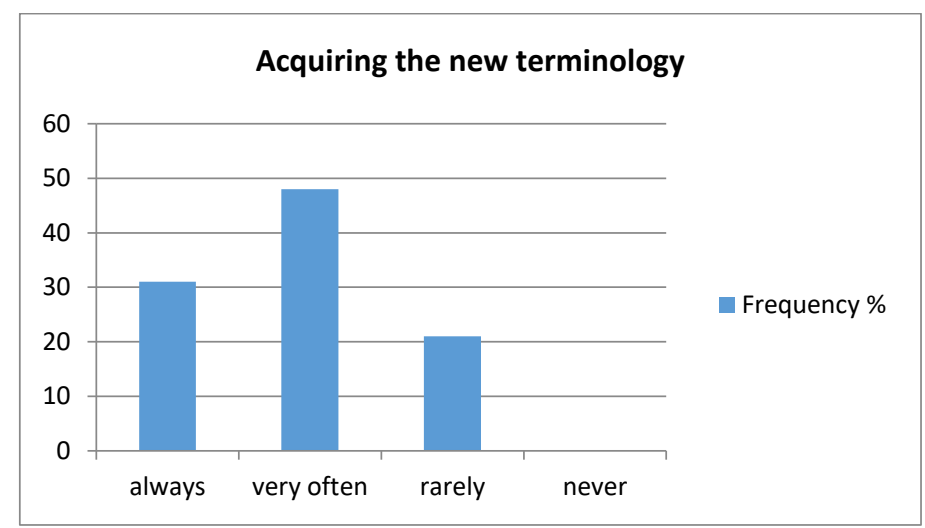

Graph 2.

Question- What strategies do you use to find the meaning of the new words?

a. guess from the context b. dictionary c. analyze parts of speech $d$. ask the help of the teacher e. consult with an expert of the field

It is important to know what approach students use to understand the meaning of new terminology. As it is clearly shown in the graph, $46 \%$ need the help of the teacher, $21 \%$ guess it from the context, $25 \%$ use the dictionary and $8 \%$ analyze parts of speech, none of them actually consults an expert of the field. From the statistics, it is clear that students lack methods of understanding new terminology from the context or by analyzing the parts of speech in the sentence.

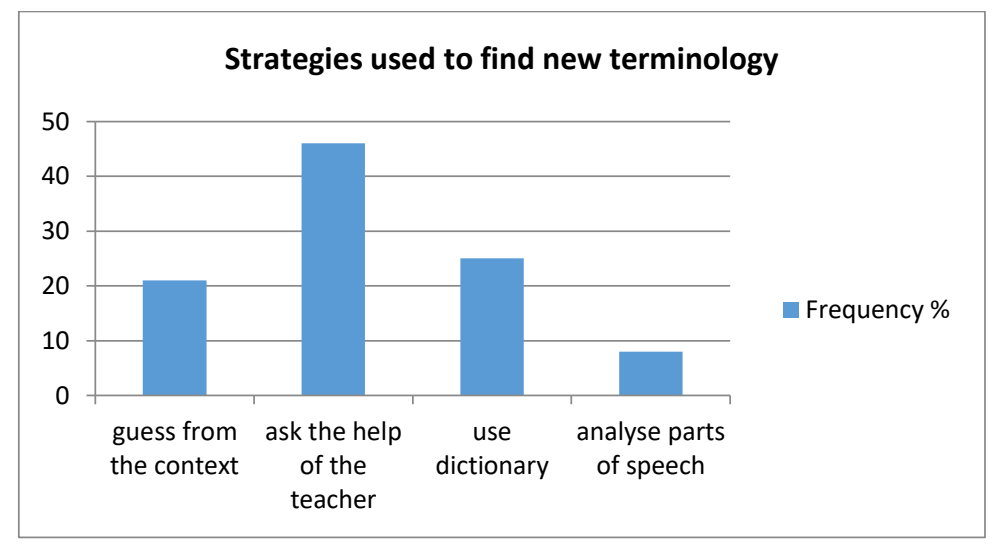

Graph 3.

Question - When I have to speak in English, I encounter difficulties in using the terminology of agriculture

As it is shown in Graph 4. $22 \%$ always, $47 \%$ very often, $28 \%$ rarely and $3 \%$ never have difficulties in using the new terminology while speaking. Speaking is another important issue which is not practiced a lot in ESP courses. Swain (1985) argues that students fail to develop their grammatical and sociolinguistic accuracy due to the fact that students had received few opportunities to produce language (Cit. Basturkemen.H., 2006). Using the language in communicative situation helps them improve the technical vocabulary they have learnt and acquire new terms. 


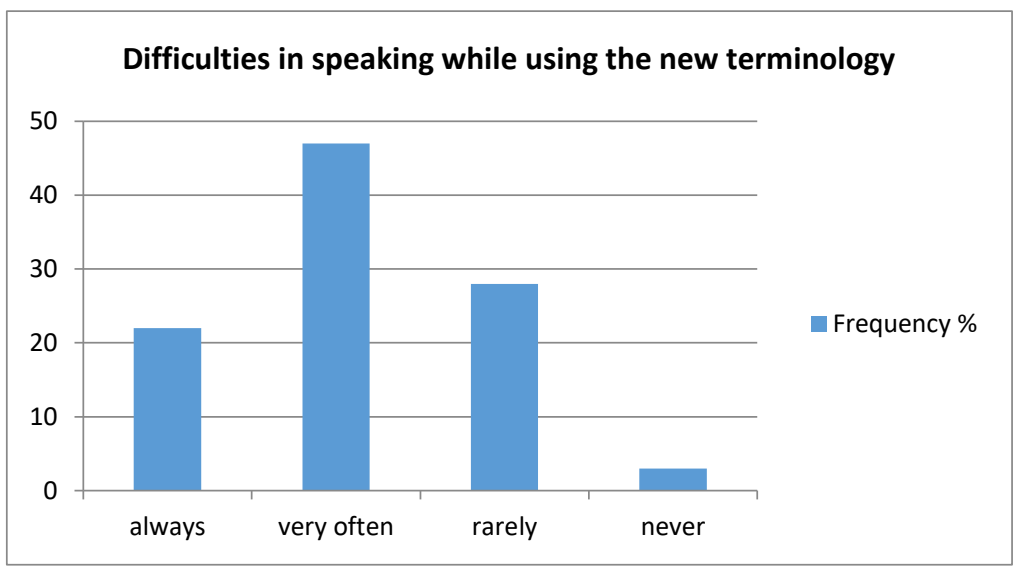

Graph 4.

The rest of the questionnaire consists of open-ended questions. In an open-ended question, students mentioned several reasons why they encounter difficulties while learning the terminology of agriculture and environment. The overwhelming reason was that they had to learn and understand it firstly in Albanian and then in English. Actually, the ESP course is being taught in the first year of Bachelor degree and consequently students do not have enough knowledge of the topics being discussed. This makes it difficult for the teachers since their scope is to develop this knowledge in English. Some other reasons mentioned were: not having a certain level of proficiency to complete the course successfully and difficulties to find the meaning of the words even though they are completely aware that the translation of the terms isn't enough to fully understand the text. What was noticed in the syllabus and mentioned by the students as well, was the lacking of listening activities in class. Listening activities contribute in the process of acquiring of new terminology.

Some activities which help the students to acquire new terminology are: use of new terminology in written and spoken form during the class activities; activities with definitions of the new words; activities with completing the gaps; activities with alternatives and sentences ordering, listening and speaking activities with topics regarding the agriculture and environment.

\section{Conclusions}

Teaching terminology in ESP requires special attention by the teachers. Thus, it is essential for the teachers to develop all the skills and strategies related to acquiring the new terminology. The main aim of the study was to understand how to deal with the new terminology and to suggest some ideas on how to facilitate the learning process. In order to have a successful result at the end of the course it is necessary to learn what ESP is, what does it represent; what role do the ESP teachers play; what can ESP teachers do to improve students' knowledge in learning the new terminology. To conclude all the difficulties that students' encounter can be reduced.

\section{Reference}

[1] Basturkmen.H., "Ideas and Option in English for Specific Purposes" Lawrence Erblaum Associates, Publisher, London 2006

[2] Dudley-Evans.T (1997) An overview of ESP in the 1990's "The Japan Conference on English for Specific Purposes Proceeding" (Aizuwakamatsu City, Fukushima, Novemeber 8, 1997)

[3] Dudley-Evans.T \& St.John.M.(1998), "Developments in English for Specific Purposes" A multi-disciplinary approach Cambridge University Press

[4] Coxhead.A., (2013) "Vocabulary and ESP" in Paltridge,B., \&Stafield,S., "The Handbook for Specific Purposes" A John Wiley \& Sons, Ltd., Publication

[5] Hutchinson.T. \& Water.A.,(1987) "English for specific purposes learning-centred approach" Cambridge University Press

[6] Montero.L.G.B., "A brief View of the ESP Approach", Letras 46 (2009) ISSN 1409-424X

[7] Musikhin I.A (2016) English for specific purposes: teaching English for Science and Technology 
[8] Nation P (2007) "The four strands" Innovation in Language Learning and Teaching Vol.1, No.1, 2007

[9] Nation.P., (2000) "Learning Vocabulary in Another Language" Cambridge Applied Linguistics, Series Editors: Carol A. Chapelle and Susan Hunston

[10] Javid Z.CH "English for Specific Purposes: Role of Learners, Teachers, and Teaching Methodologies" European Scientific Journal July 2015 Edition vol.11 No.20 ISSN: 1857-7881 (Print) e- ISSN 1857-7431

[11] Orr Thomas "The Japan Conference on English for Specific Purposes" Proceeding1997

[12] Quero.B., \& Coxhead.A.,(2018) "Using a Corpus-Based Approach to Select Medical Vocabulary for an ESP Course: The case for High-Frequency Vocabulary" in "Key Issues in English for Specific Purposes In Higher Education" Springer International Publishing Switzerland

[13] Schmitt and Schmitt (2012) "A reassessment of frequency and vocabulary size in L2 vocabulary teaching" Language Teaching/ Volume 47/Issue 04/ October 2014, pp. 484-503 